\title{
Dietary Pattern of Schoolgoing Adolescents in Urban Baroda, India
}

\author{
P.V. Kotecha', Sangita V. Patel'2, R.K. Baxi'2, V.S. Mazumdar², Misra Shobha², \\ K.G. Mehta ${ }^{3}$, Diwanji Mansi², Modi Ekta² \\ 'Country Representative, Academy for Educational Development, A2Z, The USAID Micronutrient Project India, \\ New Delhi 110 022; ²Department of Community Medicine, Baroda Medical College, Vadodara; \\ ${ }^{3}$ Department of Community Medicine, GMERS Medical College, Gotri, Vadodara, India
}

\begin{abstract}
Diet plays a very important role in growth and development of adolescents, during which the development of healthy eating habits is of supreme importance. There is a dual burden of undernutrition and overnutrition in this age-group. The study assessed the food habits, food preferences, and dietary pattern of schoolgoing urban adolescents in Baroda, India. Both quantitative and qualitative methods were used in this study. A quantitative survey was carried out using a pre-tested self-administered structured questionnaire among 1,440 students from class 6 to 12 in 7 English medium and 23 Gujarati medium schools. Focus group discussions, 5 each with adolescent boys and girls, were held, along with 5 focus group discussions with teachers of Gujarati and English medium schools. Nearly 80\% of adolescents had consumed regular food, like dal, rice, chapati, and vegetables, including green leafy vegetables. Nearly $50 \%$ of them had consumed chocolates, and about one-third consumed fast foods. Nearly $60 \%$ of adolescents had their breakfast daily while the remaining missed taking breakfast daily. Nearly one-third of adolescents were missing a meal once or twice a week. A large majority had consumed regular foods. However, more than half of them had consumed chocolates, soft drinks, and over one-third had taken fast foods.
\end{abstract}

Key words: Adolescents; Dietary pattern; Nutrition; Urban; India

\section{INTRODUCTION}

The word 'adolescence' is derived from the Latin verb 'adolescere', which means "grow to maturity." Adolescence is a grey area in the spectrum of life falling between childhood and adulthood. It is an age of transition when an individual experiences rapid growth and development, both physical and psychological and changes from being a child to an adult (1).

WHO defines adolescents as persons in the agegroup of 10 to 19 years (2). In India, there are an estimated 190 million adolescents comprising over one-fifth of the entire population (3).

Adolescence is also a period when development of

Correspondence and reprint requests:

Dr. Sangita Patel

Associate Professor

Department of Community Medicine (PSM)

Baroda Medical College

Vadodara 390001

India

Email: sangita_psm@yahoo.co.in

Fax: (0265) 2421594 the reproductive system, sexual maturation, formation of identity, and gender roles set in, and issues relating to identity, gender roles, and related problems arise (4). A study conducted by Kotecha et al. regarding identification and ranking of problems among urban adolescents could identify problems broadly into the category of health and nutrition, academic, physical growth, and development (5).

The development of healthy eating habits is important as the rapid physical growth in adolescence is associated with increased nutritional needs. Various studies on diet and nutrition intake of adolescents and young adults in the developed world have shown that their diets are often high in fats and refined carbohydrate (6).

Adolescence is also a period of increased vulnerability to obesity. Lack of physical activity and outdoor sports, along with the consumption of fatrich 'junk' foods, is the major cause of obesity among the affluent population (7).

Consumption of diet high in sugar, saturated fat, salt, and calorie content in children can lead to 
early development of obesity, hypertension, dyslipidaemia, and impaired glucose tolerance (8).

Some dietary patterns appear quite common among adolescents, to mention a few: snacking, usually on energy-dense foods; meal skipping, particularly breakfast, or irregular meals; wide use of fast food; and low consumption of fruits and vegetables (9-10).

Among urban adolescents in India, some of these patterns are also likely to be common but very little information is available. Therefore, this study was carried out among schoolgoing urban adolescents, with the objective to assess their food habits, food preferences, and dietary pattern in Baroda city, India.

\section{MATERIALS AND METHODS}

A list of area-wise distribution of the schools of Baroda city was obtained from the office of the District Education Officer (DEO). The list included 177 schools affiliated to the Gujarat Secondary Education Board. Using systematic random sampling, a sample of 30 schools from this list was selected for the study. The selected sample comprised 7 English medium and 23 Gujarati medium schools, which is similar to the proportion of English and Gujarati medium schools in Baroda. The study obtained approval from the school and was started after getting ethical clearance from Institutional Review Board (IRB) of Baroda Medical College. As the list of schools was prepared based on administrative areas, the sample had proportionate representation of all the administrative wards of the city.

\section{Study tools}

The study tools involved both quantitative and qualitative components. The study was carried out among adolescents of the selected urban schools. For quantitative component, a survey was carried out using a self-administered structured questionnaire, either in English or Gujarati, among 1,440 students who included 748 girls and 692 boys from Class 6 to 12 in 7 English medium and 23 Gujarati medium schools to include desired agegroup of 10-19 years. The questionnaire was pretested in both the languages. The selected classes were explained the purpose of the study. Participation in the study was voluntary. Self-administered questionnaire was completed by students to ensure confidentiality; the names were omitted. The instruments were collected after checking for completeness. The questionnaire was designed to assess the dietary patterns and food habits of adolescents, in which the questions were asked on the types of foods consumed in the last 24 hours (recall method), consumption of breakfast, and their habit of skipping meals.

The quantitative data collected from this selfadministered questionnaire were entered and analyzed using Epi Info (version 6.04d) software. (11) Data cleaning was carried out, checked for discrepancies, and rectified.

For qualitative component, focus group discussions (FGDs), 5 each with adolescent boys and girls were held, along with 5 focus group discussions with teachers of both Gujarati and English medium schools in either Gujarati or English language, whichever was preferred by them.

The FGDs were conducted class-wise to get an idea regarding the evolving patterns by age and note the differences. It was decided to have eight participants in each FGD. We also tried to assess their perceptions regarding healthful foods, nonhealthful foods, preferences for food, their thinking about junk food, and the barriers for adopting healthful food. Researchers conducted the FGDs, and two assistants were taking notes which were then expanded on the same day but audio-recording of the same was not done because participants did not give consent for audio-recording of FGDs. FGDs were conducted in separate rooms ensuring complete privacy to the participants.

The main purpose of adding qualitative component among teachers was mainly to find out teachers' opinion about food habits of adolescents to know the level of knowledge among the teachers about nutritional needs of adolescents, and how to improve their nutritional status. FGD transcripts were later translated into English after reviewing for accuracy. Transcripts were read several times and content analyzed using the technique of open coding. Themes were defined and identified from the text.

\section{Definition of variables}

Fast foods were defined as foods sold in a restaurant or store which are rapidly prepared and quickly served in a packaged form for taking away while junk foods were defined as energy-dense foods with high sugar/fat/salt contents and low nutrient value in terms of protein, fibre, and vitamin and mineral contents (12). 


\section{RESULTS}

\section{Quantitative findings}

A total of 1,440 students from 7 English medium and 23 Gujarati medium schools participated in the study. Of them, 353 students were from English medium and 1,087 from Gujarati medium. Table 1 shows the demographic profile of the study participants, of whom $52 \%$ (748) were girls, and $48 \%$ (692) were boys. Less number of students of Class 10 and 12 participated due to impending board examinations.

The age distribution of the adolescent boys and girls showed that half of them belonged to the age-group of 14-16 years. About one-third were in their early adolescence (11-13 years), and the rest belonged to the late adolescence group (17-19 years). The median age of both boys and girls was 14 years. Ninety-three percent of the respondents were Hindu. With regard to education of parents, nearly one-third of the fathers and one-fifth of the mothers were graduates, $32 \%$ of the mothers and $23 \%$ of the fathers were educated up to Class 10 . Overall, educational attainment was, not surprisingly, better among fathers than among mothers.

Occupational status of their mothers showed that $75 \%$ were housewives, and $7 \%$ were professionals. Among the fathers, $13 \%$ were professionals, $24 \%$ had clerical jobs, $10 \%$ had skilled technical jobs, and $21 \%$ owned a business. The average monthly family income reported was less than Rs 5,000 in $44 \%$ of the adolescents while, in about $25 \%$, it was between Rs 5,001 and 10,000 per month. The median family income was Rs 7,000.

Two-thirds of the adolescents came from nuclear families and the rest from joint families.

Table 2 shows the dietary pattern of these adolescents. Large majority of them (nearly 80\%) had consumed regular foods, like dal, rice, chapati, and vegetables, including green leafy vegetables. Nearly half of them consumed chocolates, and about onefourth consumed fast foods while 50\% consumed bakery items

Nearly $60 \%$ of adolescents had their breakfast daily whereas $13 \%$ had breakfast only 3 to 4 days a week, and $16 \%$ had their breakfast only once or twice a week, and $12 \%$ of adolescents never had breakfast (Table 3).

In this study, nearly $55 \%$ of adolescent boys and girls had habits of taking regular meals (thrice a day

\begin{tabular}{|c|c|c|}
\hline Particulars & \multicolumn{2}{|c|}{$\begin{array}{c}\text { Total }(\mathrm{N}=1,440) \\
(\%)\end{array}$} \\
\hline \multicolumn{3}{|l|}{ Sex } \\
\hline Boys & \multicolumn{2}{|c|}{$692(48)$} \\
\hline Girls & \multicolumn{2}{|c|}{$748(52)$} \\
\hline \multicolumn{3}{|l|}{$\begin{array}{l}\text { Age (in completed } \\
\text { years) }\end{array}$} \\
\hline $11-13$ & \multicolumn{2}{|c|}{$512(35.6)$} \\
\hline $14-16$ & \multicolumn{2}{|c|}{733 (50.9) } \\
\hline $17-20$ & \multicolumn{2}{|c|}{$195(13.5)$} \\
\hline Mean & \multicolumn{2}{|c|}{14.4 years } \\
\hline Median & \multicolumn{2}{|c|}{14 years } \\
\hline \multicolumn{3}{|l|}{ Type of family } \\
\hline Nuclear & \multicolumn{2}{|c|}{$936(65)$} \\
\hline Joint & \multicolumn{2}{|c|}{$504(35)$} \\
\hline \multicolumn{3}{|l|}{ Religion } \\
\hline Hindu & \multicolumn{2}{|c|}{ 1,339 (93) } \\
\hline Muslim & \multicolumn{2}{|c|}{$45(3)$} \\
\hline Christian & \multicolumn{2}{|c|}{$28(2)$} \\
\hline Other & \multicolumn{2}{|c|}{$28(2)$} \\
\hline Educational quali- & Father & Mother \\
\hline Non-literate & $3(0.2)$ & 27 (1.9) \\
\hline Class 7 & $128(8.9)$ & $200(13.9)$ \\
\hline Class 10 & $335(23.2)$ & $461(32.0)$ \\
\hline Class 12 & $226(15.7)$ & $171(11.9)$ \\
\hline Graduation & $421(29.2)$ & $292(20.3)$ \\
\hline $\begin{array}{l}\text { Postgraduation } \\
\text { and higher }\end{array}$ & $120(8.3)$ & $75(5.2)$ \\
\hline Others & $64(9.9)$ & $72(5.0)$ \\
\hline No response & $143(4.4)$ & $142(9.8)$ \\
\hline Family income & \multicolumn{2}{|c|}{$\mathrm{N}=1097(\%)$} \\
\hline $\begin{array}{l}\text { Less than } \\
\text { Rs } 5,000\end{array}$ & \multicolumn{2}{|c|}{$479(43.7)$} \\
\hline Rs $5,001-10,000$ & \multicolumn{2}{|c|}{$271(24.7)$} \\
\hline Rs $10,001-15,000$ & \multicolumn{2}{|c|}{$108(9.8)$} \\
\hline Rs $15,001-20,000$ & \multicolumn{2}{|c|}{$67(6.1)$} \\
\hline Rs $20,001-25,000$ & \multicolumn{2}{|c|}{$35(3.2)$} \\
\hline Rs $25,001-30,000$ & \multicolumn{2}{|c|}{$29(2.6)$} \\
\hline $\begin{array}{l}\text { Beyond } \\
\text { Rs. } 30,000\end{array}$ & \multicolumn{2}{|c|}{$108(9.8)$} \\
\hline No response & \multicolumn{2}{|c|}{343} \\
\hline
\end{tabular}

and not a single meal skipped in entire week) but $30 \%$ of boys and $40 \%$ of girls missed a meal once or twice a week whereas $5 \%$ of adolescents missed their meals 3 to 4 times a week (Table 4 ). 


\begin{tabular}{|c|c|c|}
\hline Chapati/bhakhari & 1,242 & 86.3 \\
\hline Rice & 1,164 & 80.8 \\
\hline Dal & 1,091 & 75.8 \\
\hline Milk & 1,081 & 75.1 \\
\hline Green leafy vegetables & 1,082 & 75.1 \\
\hline Fruits and fruit juice & 914 & 63.5 \\
\hline Other vegetables & 828 & 57.5 \\
\hline Chocolate/pastries/sweet & 811 & 56.3 \\
\hline Papads and pickles & 754 & 52.4 \\
\hline $\begin{array}{l}\text { Biscuits or other bakery } \\
\text { items, like bread, toast, }\end{array}$ & & \\
\hline buns, etc. & 726 & 50.4 \\
\hline Beans/legumes & 664 & 46.1 \\
\hline Salads & 587 & 40.8 \\
\hline Parata/puri & 578 & 40.1 \\
\hline Cold drinks/soft drinks & 564 & 39.2 \\
\hline $\begin{array}{l}\text { Potato chips/namkeens/ } \\
\text { deep-fried snacks }\end{array}$ & 553 & 38.4 \\
\hline Ice cream/milkshake/paneer & 519 & 36.0 \\
\hline Cheese/butter & 440 & 30.6 \\
\hline $\begin{array}{l}\text { Pizza/burger/Frankie or any } \\
\text { other fast food (including }\end{array}$ & & \\
\hline Chinese food) & 351 & 24.4 \\
\hline Egg & 317 & 22.0 \\
\hline Meat/fish/chicken & 190 & 13.2 \\
\hline
\end{tabular}

chana), fruits, and drinking milk. However, among a few students, the knowledge regarding healthful foods was lacking.

A 14 years old girl studying in a Guajarati medium school mentioned "Eating Pani puri from lari" (street-food) as a healthful food.

Junk foods

When asked to give their definitions and perceptions of junk food, they did so not only in terms of content but also in terms of their consequences. Adolescents attributed the following characteristics to junk food: high in sugar, fat, and calories; bad for health, and lacking nutritional value.

Specific foods listed as junk food included: chocolates, potato chips, soft drinks, cookies, cake, brownies, pizza, ice cream, and French fries.

A boy from Class 7 in an English medium school said that he liked to eat chocolates, and he also offered the same to his peers. In his words, "I love chocolates, and I eat chocolates daily and also give (these) to my friends, and so they call me chocolate boy."

Food preference

To give us a better understanding of food preferences of adolescents, almost unanimous response was

Table 3. Consumption pattern of breakfast among boys and girls

\begin{tabular}{|c|c|c|c|c|c|c|c|c|c|}
\hline \multirow{2}{*}{ Gender } & \multicolumn{2}{|c|}{ Daily } & \multicolumn{2}{|c|}{ 3-4 days a week } & \multicolumn{2}{|c|}{ 1-2 day(s) a week } & \multicolumn{2}{|c|}{ Never } & \multirow{2}{*}{$\frac{\text { Total }}{\mathrm{N}}$} \\
\hline & $\mathrm{N}$ & $\%$ & $\mathrm{~N}$ & $\%$ & $\mathrm{~N}$ & $\%$ & $\mathrm{~N}$ & $\%$ & \\
\hline Boys & 409 & 59.1 & 100 & 14.5 & 111 & 16.0 & 72 & 10.4 & 692 \\
\hline Girls & 429 & 57.4 & 88 & 11.8 & 121 & 16.2 & 110 & 14.7 & 748 \\
\hline Total & 838 & 58.2 & 188 & 13.1 & 232 & 16.1 & 172 & 12.6 & 1,440 \\
\hline
\end{tabular}

\begin{tabular}{|c|c|c|c|c|c|c|c|c|c|}
\hline \multirow{2}{*}{ Gender } & \multicolumn{2}{|c|}{ Never } & \multicolumn{2}{|c|}{ 1-2 times a week } & \multicolumn{2}{|c|}{ 3-4 times a week } & \multicolumn{2}{|c|}{ No response } & \multirow{2}{*}{$\frac{\text { Total }}{\mathrm{N}}$} \\
\hline & $\mathrm{N}$ & $\%$ & $\mathrm{~N}$ & $\%$ & $\mathrm{~N}$ & $\%$ & $\mathrm{~N}$ & $\%$ & \\
\hline Boys & 418 & 60.4 & 194 & 28.0 & 34 & 4.9 & 46 & 6.6 & 692 \\
\hline Girls & 380 & 50.8 & 297 & 39.7 & 34 & 4.5 & 37 & 4.9 & 748 \\
\hline Total & 798 & 55.4 & 491 & 34.1 & 68 & 4.7 & 83 & 5.8 & 1,440 \\
\hline
\end{tabular}

\section{Qualitative findings}

Following themes emerged during FGDs with adolescents.

\section{Healthy eating habit}

When adolescents were asked about meaning of healthy eating, majority of them correctly responded that healthy eating habits meant eating green leafy vegetables, nuts, sprouted pulses (mung, "fast foods, junk food, and sweets." When asked what adolescents tend not to eat, the majority said, "fresh or cooked green leafy vegetables and fruits."

In our study, adolescents reported unhealthy eating patterns, and their food preferences were high in fat, salt, and sugar. If these food patterns (diets high in salt and fat and low in fruits, vegetables, and fibre) continue, these could pose a risk of chronic illnesses, especially obesity, heart attack, and probably cancer. 
A 13-year old boy from English medium school mentioned, "Although my weight is $70 \mathrm{~kg}$ and my parents have restricted the frequency of junk foods, I love pizza, and I can't control my desire for this, and so, I still consume it frequently."

\section{Barriers to improving the diet}

We were interested in identifying the barriers that prevented adolescents from acting upon their knowledge and practising more healthful dietary behaviours. Time was reported as the major barrier to improving the diet. Many of the adolescents told us, "We are so busy that we don't have enough time to change the food habits due to school and tuitions."

An important barrier mentioned by a girl of Class 9 from Guajarati medium school was expressed, thus: "I need to reach tuition at 6 o'clock in the morning everyday, and so, I have no time to take breakfast except on Sundays."

Some students also mentioned, "Many of us have preferences and strong desire to eat junk food and lack of desire to eat healthful food, even though we know the consequences of eating the junk food."

While conducting FGDs with teachers, we incorporated three important issues: importance of nutrition in their students (adolescents), their eating habits, and how they could improve the eating habits of adolescents. Most of the teachers mentioned correctly that phase of adolescence is associated with rapid growth and development and, therefore, balanced diet is essential and failure to do so causes anaemia (occhu lohi: less blood), obesity (motapanu: fat), and other diseases, like diarrhoea and vomiting.

One of the teachers from an English medium school reported, "Many adolescent girls are selfconscious about their looks, and so they eat food in less quantity, and we call it Aishwaria Rai Syndrome (named after a famous actress and Miss World: so, all girls treat her as their idol) whereas it is totally the opposite among boys; they just want to build their bodies and want to become real men, which we call Salman Khan Syndrome (named after a famous actor with muscular build-up: so, all boys treat him as their idol). They are not able to differentiate between being muscular or fat."

Few of the teachers advised their students about regularity of meals, eating healthful foods, like dal, rice, sabji, roti, sprouted seeds, buttermilk, green leafy vegetables, and fruits, not skipping meals or breakfast, and avoiding street-foods.

\section{DISCUSSION}

Our study showed that a good number of adolescents had a healthy dietary pattern. However, more than half of them consumed chocolates, soft drinks, and over one-third had other fast foods as well, which is an area of concern.

In Nepal, a study among school children revealed that fast foods (ready-to-eat snacks, chips, etc.) were referred by more than two-thirds of them and that advertising influenced preferences in 80\% (13).

A study by Punjab Agricultural University, Ludhiana, on consumption pattern of fast foods among teenagers found that fast foods are most commonly consumed between regular meals (14).

A study on the diet and nutritional status of adolescent tribal population in nine states of India found that the mean intake of all the foodstuffs, especially the income-elastic foods, such as pulses, milk and milk products, oils and fats, and sugar and jiggery, was lower than the recommended levels of Indian Council of Medical Research (ICMR) (15).

Another study of the dietary pattern, nutrient intake, and growth of adolescent girls in urban Bangladesh noticed that a substantial proportion of girls did not consume eggs (26\%), milk (35\%), or dark-green leafy vegetables (20\%), which concurs with our findings where girls did not consume important dietary components (16).

A study on the diet quality and nutritional status of rural adolescent girls in North India assessed that subjects followed a two-meal pattern, and their diets were monotonous and cereal-based. The mean daily intake of milk and milk products, pulses, green leafy vegetables, other vegetables, and fruits were grossly inadequate (17).

In our study, majority of the boys and girls had breakfast regularly. A point of concern, however, was that $40 \%$ girls and 30\% boys were missing a meal once or twice a week, mainly because they were fasting or did not have time. Some missed their meals due to ill health, lack of appetite, or disliking the food served.

In the focus group discussions, most boys correctly mentioned good and common sources of energy (such as milk, ghee, wheat, bajri, rice, and pulses) and vitamins (such as green leafy vegetables, fruits, and carrots) as healthful foods. Girls could correctly point out certain cooking/food preparation practices which led to the reduction in nutritive value of 
the food items, for instance, excessive washing of rice grains.

Most boys and girls considered stale fast foods and uncovered foods available from outside as nonhealthful foods. Some of them even spoke against consumption of fried foods, soft drinks, chocolate, tea, and coffee while others admitted getting more attracted towards fast foods than homemade foods, especially when they were out with friends.

We noticed a big gap between their knowledge and practice. Despite knowing the harmful effects of unhealthy food habits, they continued to eat junk foods and the reasons being their taste preferences and strong desire to do so. Another barrier to proper healthy food habit was lack of time due to their busy schedule.

Another study relating to dietary patterns of adolescents found that the food habits during adolescence were affected by the opportunities they had of eating with peers-away from their families (18).

Most teachers felt that adolescents paid more attention to their looks; among girls to remain slim and attractive whereas among boys to appear well-built. Due to such incorrect beliefs, they did not adopt healthy eating habits.

\section{Conclusions}

A large number of adolescents had a healthful diet and consumed regular foods. However, more than half of them consumed chocolates, soft drinks, and over one-third consumed other fast foods as well or missed a meal once or twice a week. Most boys and girls were aware of healthful and non-healthful foods. Although they were aware of the potentially-harmful effects of fast foods, they admitted a tendency to eat such foods when they were out with their friends.

\section{Recommendations}

Based on the findings of the present study, following recommendations emerge:

1. While the food consumption includes most of the desired items, the pattern suggests that the frequency of intake of fast foods is more than desired and needs to be curtailed.

2. Regularity of food consumption is another point that needs to be stressed as $40 \%$ missed their breakfast, and $45 \%$ missed their regular meals once or more often in a week in our study, and that was found more in girls than in boys.
3. There is a need for nutrition counselling to bridge the gap between knowledge and practice. Adolescents knew what is regular and good food but their practice showed that they did not quite follow the dietary pattern that they considered good because of the social factors on one side and less-perceived importance of the regular and quality food on the other.

\section{ACKNOWLEDGEMENTS}

We express our sincere thanks to the Government of India and World Health Organization, India Office, for funding this study. We thank Dr. Arvind Mathur, National Program Officer, WHO, India, for providing technical guidance.

\section{REFERENCES}

1. Bhave SY, Nair MKC. Course manual for adolescent health. Part-II: Indian perspective. In: Bhave SY, editor. Adolescent health. New Delhi: Indian Academy of Pediatrics, 2002:7-11.

2. Nair MKC. Training materials for conducting family life education sessions for adolescents. Teens 2002;2:45-72.

3. Jejeebhoy SJ. Adolescent sexual and reproductive behavior: a review of the evidence from India. Soc Sci Med 1998;46:1275-90.

4. Nath A, Garg S. Adolescent friendly health services in India: a need of the hour. Indian J Med Sci 2008;62:46572.

5. Kotecha PV, Patel S, Mazumdar VS, Baxi RK, Misra $\mathrm{S}$, Mehta KG et al. Identification and ranking of problems perceived among urban school going adolescents in Vadodara in India. Indian J Clin Pract 2011;21:555-65.

6. Bull NL. Studies of the dietary habits, food consumption and nutrient intakes of adolescents and young adults. World Rev Nutr Diet 1988;57:24-74.

7. Choudhury P, Gogia S. Nutrition issues in adolescence. In: Bhave SY, editor. Bhave's textbook of adolescent medicine. New Delhi: Jaypee Brothers Medical Publications, 2006:18-9.

8. Tnn SS. Indian food worse than western junk. Times of India 2007 March 13. (http://articles.timesofindia. indiatimes.com/2007-03-13/india/27875574_1_fatstfa-content-vanaspati, accessed on 21 October 2013).

9. Cavadini C, Decarli B, Dirren H, Cauderay M, Narring F, Michaud P-A. Assessment of adolescent food habits in Switzerland. Appetite 1999;32:97-106.

10. Dausch JG, Story M, Dresser C, Gilbert GG, Portnoy B, Kahle LL. Correlates of high-fat/low-nutrientdense snack consumption among adolescents: results 
from two national health surveys. Am J Health Promot 1995;10:85-8.

11. Dean AG, Coulombier D, Brendel KA, Smith DC, Burton AG, Dicker RC et al. Epi Info version 6.04. A word processor, database and statistical programme for public health on IBM compatible microcomputers. Atlanta, GA: Centers for Disease Control and Prevention, 2001.

12. Kaushik JS, Narang M, Parakh A. Fast food consumption in children. Indian Pediatr 2011;48:97-101.

13. Sharma I. Trends in the intake of ready-to-eat food among urban school children in Nepal. SCN News 1998;16:21-2.

14. Sadana B, Khanna M, Mann SK. Consumption pattern of fast foods among teenagers. Appl Nutr 1997;22:41-5.
15. Rao KM, Balakrishna N, Laxmaiah A, Venkaiah K, Brahmam GNV. Diet and nutritional status of adolescent tribal population in nine states of India. Asia Pac J Clin Nutr 2006;15:64-71.

16. Ahmed F, Zareen M, Khan MR, Banu CP, Haq MN, Jackson AA. Dietary pattern, nutrient intake and growth of adolescent school girls in urban Bangladesh. Public Health Nutr 1998;1:83-92.

17. Malhotra A, Passi SJ. Diet quality and nutritional status of rural adolescent girl beneficiaries of ICDS in North India. Asia Pac J Clin Nutr 2007;16(Suppl 1):816.

18. Trusswell AS, Hill ID. Course manual for adolescent health. Part-II: Indian perspective. In: Bhave SY, editor. Adolescent health. New Delhi: Indian Academy of Pediatrics, 2002:51-7. 